\title{
Sweat output measurement of the post-ganglion sudomotor response by Q-Sweat Test: a normative database of Chinese individuals
}

Shu-Fang Chen ${ }^{1,2+}$, Ya-Ting Chang ${ }^{1 \dagger}$, Cheng-Hsien Lu1 ${ }^{1}$, Chi-Ren Huang ${ }^{1}$, Nei-Wen Tsai ${ }^{1}$, Chiung-Chih Chang ${ }^{1,2}$, Chih-Cheng Huang ${ }^{1}$, Yao-Chung Chuang ${ }^{1 *}$ and Wen-Neng Chang ${ }^{1 *}$

\begin{abstract}
Background: Q-Sweat is a model used for evaluating the post-ganglionic sudomotor function by assessing sweat response. This study aimed to establish the normative database of Q-Sweat test among Chinese individuals since this type of information is currently lacking.

Results: One hundred and fifty (150) healthy volunteers, 76 men and 74 women with age range of 22-76 years were included. Skin temperature and sweat onset latency measured at the four sites (i.e., the forearm, proximal leg, distal leg, and the foot) did not significantly correlate with age, gender, body height (BH), body weight (BW), and body mass index (BMI) but the total sweat volume measured in all four sites significantly correlated with sex, $\mathrm{BH}$, and BW. Except for the distal leg, the total sweat volume measured at the other three sites had a significant correlation with BMI. In terms of gender, men had larger total sweat volume, with median differences at the forearm, proximal leg, distal leg, and foot of $0.591 \mu \mathrm{l}, 0.693 \mu \mathrm{l}, 0.696 \mu \mathrm{l}$, and $0.358 \mu \mathrm{l}$, respectively. Regarding BW difference $(\geq 62$ and $<62 \mathrm{Kg}$ ), those with BW $\geq 62 \mathrm{Kg}$ had larger total sweat volume. Median differences at the forearm, proximal leg, distal leg, and foot were $0.538 \mu \mathrm{l}, 0.744 \mu \mathrm{l}, 0.695 \mu \mathrm{l}$, and $0.338 \mu \mathrm{l}$, respectively. There was an uneven distribution of male and female participants in the two BW groups. In all conditions, the total sweat volume recorded at the foot site was the smallest.
\end{abstract}

Conclusion: This is the first report to show the normative database of sweat response in Chinese participants evaluated using Q-Sweat device. This normative database can help guide further research on post-ganglionic sudomotor or related clinical practice involving a Chinese population.

Keywords: Age, Body height, Body mass index, Body weight, Chinese, Gender, Normative database, Q-Sweat, Sweat output

\section{Background}

Autonomic nervous system (ANS) dysfunction may manifest in a variety of symptoms, including changes in sweating, either in an increased or decreased manner. Currently, sweat production, a sudomotor response of ANS, can be measured using several tools such as thermoregulatory sweat testing (TST), quantitative sudomotor axon reflex testing (QSART), silicone impressions,

\footnotetext{
* Correspondence: ycchuang@cgmh.org.tw; cwenneng@ms19.hinet.net ${ }^{\dagger}$ Equal contributors

'Department of Neurology, Kaohsiung Chang Gung Memorial Hospital and Chang Gung University College of Medicine, Kaohsiung, Taiwan

Full list of author information is available at the end of the article
}

sympathetic skin response (SSR), acetylcholine (Ach) sweat-spot test, and quantitative direct and indirect axon reflex testing (QDIRT) [1,2]. The QSART, designed by Low et al. [3], is used clinically to evaluate postganglionic sudomotor function by measuring the axonal reflex-mediated sweat response over time, with the stimulation of sweat glands by $10 \%$ Ach. It is sensitive and reproducible in both controls and subjects with neuropathies [3-7]. The Q-Sweat is a commercial quantitative sweat measurement system which examines the indirect sweat response, is modeled on QSART [8]. A study conducted by Sletten et al. [8] to investigate the sweat response using Q-Sweat and QSART recording

\section{Biomed Central}


under identical conditions in healthy normal controls shows significantly lower volumes in each of the four measured sites. This comparative result can be used to estimate the expected QSART volume given an observed Q-Sweat volume, although it is preferable to use the Q-Sweat normative database directly. So far, the normal databases of the QSART and Q-Sweat are often limited to Caucasians $[7,8]$ and there is a lack of a normative database for Asians. The aim of this study was to establish the normal databases of sudomotor function among the Chinese using the Q-Sweat device, and to examine the factors that may influence the total volume of sweat response.

\section{Methods}

\section{Participants}

After approval of the Ethics Committee of Chang Gung Memorial Hospital (IRB 98-0805B), 150 healthy volunteers (76 men, 74 women) aged 22-76 years were examined by a neurologist before participating in the study. All were free of systemic diseases that might affect the ANS and were not taking any medicine that might affect autonomic functions (e.g., aspirin, alpha-blocker, betablocker, calcium channel blocker, cholinergic or anticholinergic agents, and anti-acetylcholinesterase and serotonergic agents). Tea and coffee consumption, and smoking were also not allowed at least one day prior to the test. None of the participants had any dermatologic illnesses including skin injuries, or was a substance abuser. Each participant provided written informed consent. All of them were examined in the morning time, and their age, gender, body weight (BW), body height $(\mathrm{BH})$ and body mass index (BMI) were checked on the day of the study.

\section{Procedures and recordings}

The Q-Sweat studies were performed under controlled room temperature and humidity with a Q-sweat device (WR Medical Elextronics Co., Stillwater, Minnesota, USA). During the examination, the participant was placed in a supine position and underwent Q-Sweat recordings on the left side of body only because it was assumed that there would be no difference in ANS evaluation between the right and left sides [9].

In the study, four skin regions, as suggested [1,9-11] were recorded in a fixed manner (Figure 1). These were the skin surface of the medial forearm (innervated by the ulnar nerve), the proximal leg (innervated by the peroneal nerve), the distal leg (innervated by the saphenous nerve), and the proximal foot over the extensor digitorum brevis (innervated by the sural nerve). Before the study, the four skin regions were cleaned with soap and water, and thoroughly dried with absorbent paper and shaved if necessary. The regional limb skin temperature was recorded

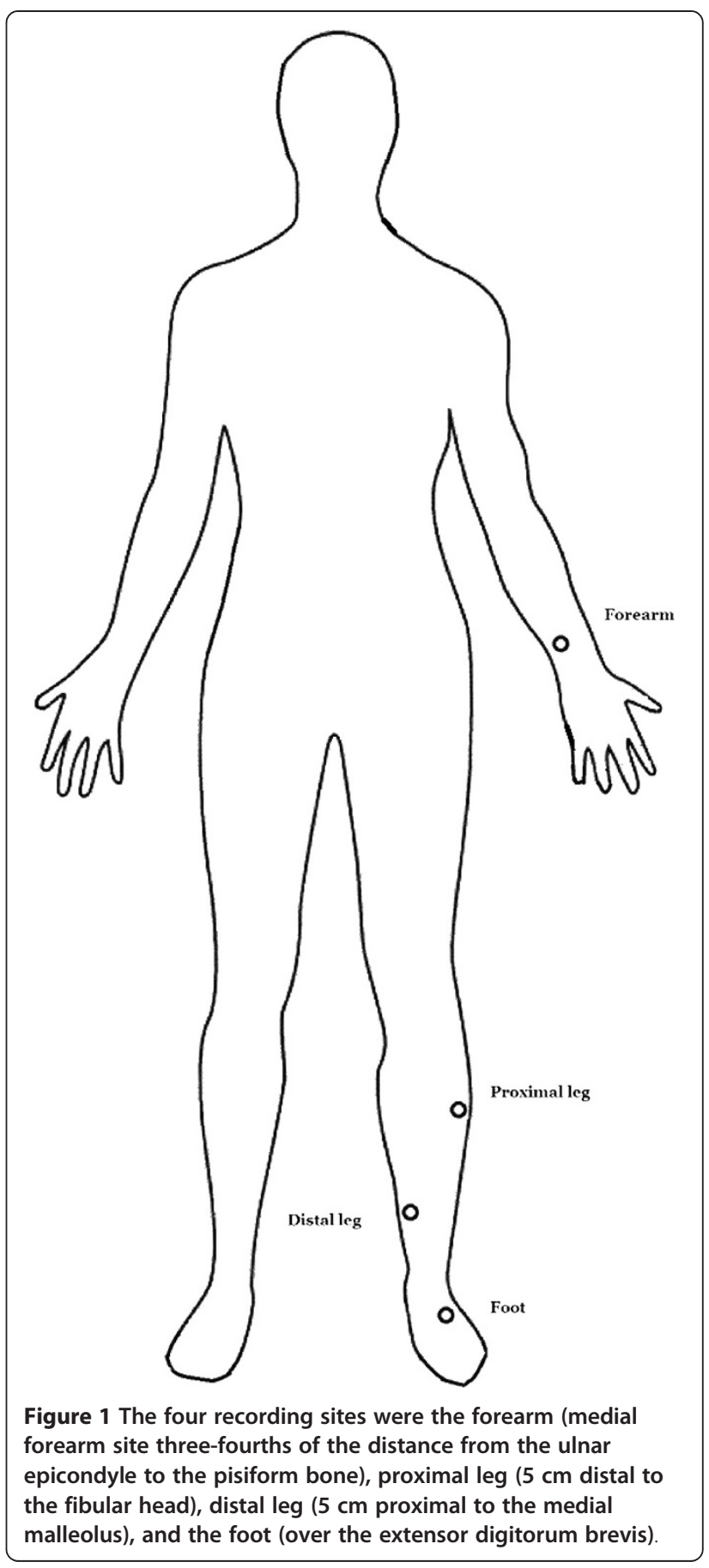

by infrared thermometer. If it was $<30.0^{\circ} \mathrm{C}$, the examined limbs were warmed-up with ultra-red heat lamp, but not $>33.5^{\circ} \mathrm{C}$ in order to ensure adequate blood flow while remaining below the limb sweating threshold [4]. The agent used for evoking the sweat response was $10 \% \mathrm{w} / \mathrm{v}$ Ach solution, which was applied to fill the chamber of the Meridian electrode (PN\#5191, WR Medical Electronics Co.) that was affixed to the skin at the test site. 
The full description of the Q-Sweat device can be obtained from the manufacturer (WR Medical Electronics Co.). This study followed the recording procedure described in the report of Sletten et al. [8]. Briefly, the Q-Sweat device used a desiccant pack (\#5190; WR Medical Electronics Co., Stillwater, Minnesota, USA) as its dry air source. Room air was drawn in through an intake pump and channeled through a serpentine of drierite (W. A. Hammond Co., Xenia, Ohio). This air was then passed through a set of sensors (Honeywell International, Inc., Morristown, New Jersey) that controlled the flow rate. The sensors evaluated the temperature and percentage of relative humidity. Lastly, the dried air was delivered to the capsule assembly and applied to the regional skin. Moisture released from the human eccrine sweat gland was picked up by the dried room air and returned to the main unit of the device via Teflon-lined Tygon tubing. The sensors again evaluated the temperature and percent relative humidity along with flow rate. These values were compared to the baseline (initial) values and integrated using the vapor pressure calculation for water between $0^{\circ} \mathrm{C}$ and $50^{\circ} \mathrm{C}$.

Sweat rate, expressed as nano-liters per minute was then displayed using the TestWorks software (WR Medical Electronics Co., Stillwater, Minnesota, USA). A constant-current stimulator, the Iontophor II (Model 6111 PM/DX, Life Tech, Inc. Stafford, Texas), was used in conjunction with the Q-Sweat device. Sweat amount and onset time of response were displayed using TestWorks software. Both sweat latency and volume were recorded. The latency measurement was the "on" time of the noticeable sweat rate change after the stimulation, and was displayed as minutes. The volume measurement was the sweat response from the time of onset latency to the end of $5 \mathrm{~min}$ stimulation and another $5 \mathrm{~min}$ recording (total of $10 \mathrm{~min}$ recording), and was displayed as micro-liters per $10 \mathrm{~min}$.

\section{Statistical analysis}

For statistical analysis, the Statistical Package for Social Sciences (SPSS) software package (version 13 for
Windows ${ }^{\circledR}$, SPSS Inc, Chicago, IL) was used. All of the data were displayed as median (minimum, maximum). Differences in basic demographic data (i.e., $\mathrm{BH}, \mathrm{BW}$, BMI, room temperature, and room humidity) between genders was calculated by the Mann-Whitney $U$ test and together with skin temperature, onset latency and total volume of sweat response, were check by the Spearman correlation analysis. A two-tailed $p<0.01$ was considered significant.

Before entering the linear regression, the sweat volumes were tested for normality by the KolmogorovSmirnov test and were calculated by square root to transform them into normal distribution. Linear regression was introduced to check the significant varieties revealed by the Spearman correlation in a "Stepwise Method" for all of the varieties. The equations, $R$ and R-squared were calculated. Differences in skin temperature, onset latency and volume at each of the four sites by gender and by BW (cut- off point $62 \mathrm{Kg}$ ) were checked by the Mann-Whitney $U$ test, while the Kruskal-Wallis Test was used to check the differences in five age ranges (i.e., 20-30, 30-40, 40-50, 50-60 and $\geq 61$ years). A $p<0.05$ was considered significant.

\section{Results}

The demographic data of the 150 healthy participants showed significant differences in $\mathrm{BH}, \mathrm{BW}$, and BMI between sexes (Table 1). Results of the respective correlation analyses between the sweat output responses and age, gender, BH, BW, and BMI are listed in Table 2. Skin temperatures and sweat onset latencies at the four measured sites did not significantly correlate with age, sex, $\mathrm{BH}, \mathrm{BW}$, and BMI. However, the total volume of sweat response measured on all four sites significantly correlated to gender, $\mathrm{BH}, \mathrm{BMI}$ and $\mathrm{BW}$. After multiple linear regression analysis, BW was the factor that influenced the sweat volume measured on all four sites and was the only factor that positively correlated with the total volume of sweat response measured at the forearm, and proximal and distal leg. Thus, the higher BW meant larger sweat volume (Tables 3 and 4). Between partici-

Table 1 Demographic data of the participants $(n=150)$

\begin{tabular}{|c|c|c|c|c|}
\hline & Total & Woman & Man & Sig. \\
\hline Number & 150 & 74 & 76 & \\
\hline Age & $44.0(22.0,76.0)$ & $44.5(22.0,76.0)$ & $43.0(24.0,73.0)$ & 0.758 \\
\hline Body Height (m) & $1.64(1.45,1.84)$ & $1.56(1.45,1.68)$ & $1.71(1.53,1.84)$ & $0.000^{*}$ \\
\hline Body Weight (Kg) & $61.0(45.0,95.0)$ & $55.0(45.0,87.8)$ & $69.5(53.0,95.0)$ & $0.000^{*}$ \\
\hline Body mass index & $22.7(17.1,35.6)$ & $21.6(17.1,35.6)$ & $23.5(17.9,34.9)$ & $0.000^{*}$ \\
\hline Room wet (\%) & $56.0(49.0,61.0)$ & $56.0(49.0,60.0)$ & $56.0(54.0,61.0)$ & 0.593 \\
\hline Room temperature $\left({ }^{\circ} \mathrm{C}\right)$ & $23.0(19.0,27.0)$ & $23.0(20.0,27.0)$ & $23.0(19.0,26.0)$ & 0.800 \\
\hline
\end{tabular}

Data presented as median (maximum, minimum).

Abbreviations: $\mathrm{m}$, meter; $\mathrm{Kg}$, kilogram; Sig, significance (tested by Mann-Whitney $U$ test).

*Significant correlation at the 0.05 level (2-tailed). 
Table 2 Results of correlation analysis between the sweat output response and demographic data

\begin{tabular}{|c|c|c|c|c|c|c|c|c|c|c|}
\hline \multirow{2}{*}{$\begin{array}{l}\text { Spearman's rho } \\
\text { Correlations }\end{array}$} & \multicolumn{2}{|c|}{ Gender } & \multicolumn{2}{|c|}{ Age } & \multicolumn{2}{|c|}{ Body Height } & \multicolumn{2}{|c|}{ Body Weight } & \multicolumn{2}{|c|}{ Body Mass Index } \\
\hline & Cor. Coe. & Sig. & Cor. Coe. & Sig. & Cor. Coe. & Sig. & Cor. Coe. & Sig. & Cor. Coe. & Sig. \\
\hline \multicolumn{11}{|c|}{ Skin temperature $\left({ }^{\circ} \mathrm{C}\right)$} \\
\hline Forearm & 0.057 & 0.486 & 0.066 & 0.422 & 0.021 & 0.796 & -0.049 & 0.796 & -0.098 & 0.231 \\
\hline Proximal leg & 0.182 & 0.026 & 0.190 & 0.020 & 0.109 & 0.183 & -0.033 & 0.686 & -0.033 & 0.686 \\
\hline Distal leg & 0.132 & 0.107 & 0.145 & 0.077 & 0.079 & 0.339 & 0.027 & 0.742 & -0.056 & 0.496 \\
\hline Foot & -0.012 & 0.885 & -0.007 & 0.934 & -0.054 & 0.515 & 0.120 & 0.144 & 0.180 & 0.028 \\
\hline \multicolumn{11}{|l|}{ Latency (min) } \\
\hline Forearm & -0.044 & 0.593 & -0.140 & 0.087 & -0.018 & 0.829 & -0.115 & 0.162 & -0.173 & 0.034 \\
\hline Proximal leg & -0.145 & 0.077 & -0.055 & 0.502 & -0.092 & 0.263 & -0.103 & 0.210 & -0.091 & 0.269 \\
\hline Distal leg & -0.143 & 0.081 & -0.165 & 0.044 & -0.119 & 0.146 & -0.101 & 0.219 & 0.035 & 0.671 \\
\hline Foot & 0.007 & 0.928 & 0.077 & 0.150 & -0.096 & 0.244 & -0.067 & 0.416 & -0.010 & 0.905 \\
\hline \multicolumn{11}{|l|}{ Volume $(\mu \mathrm{l})$} \\
\hline Forearm & 0.366 & $0.000^{*}$ & 0.170 & 0.037 & 0.287 & $0.000^{*}$ & 0.447 & $0.000^{*}$ & 0.357 & $0.000^{*}$ \\
\hline Proximal leg & 0.448 & $0.000^{*}$ & -0.064 & 0.436 & 0.397 & $0.000^{*}$ & 0.466 & $0.000^{*}$ & 0.282 & $0.000^{*}$ \\
\hline Distal leg & 0.496 & $0.000^{*}$ & -0.139 & 0.090 & 0.467 & $0.000^{*}$ & 0.478 & $0.000^{*}$ & 0.219 & $0.007^{*}$ \\
\hline Foot & 0.455 & $0.000^{*}$ & -0.218 & $0.007^{*}$ & 0.441 & $0.000^{*}$ & 0.514 & $0.000^{*}$ & 0.309 & $0.000^{*}$ \\
\hline
\end{tabular}

Abbreviations: Sig, significance (tested by Spearman's rho correlation analysis); Cor Coe, Correlation coefficient.

*Correlation was significant at the 0.01 level (2-tailed).

pants with $\mathrm{BW} \geq 62 \mathrm{Kg}$ and those with $\mathrm{BW}<62 \mathrm{Kg}$, gender, $\mathrm{BH}$ and $\mathrm{BMI}$ were significantly different (Table 5 ).

The sweat responses presented as skin temperature, onset latency, and total volume of sweat response by gender and $\mathrm{BW}(\geq 62 \mathrm{Kg}$ and $<62 \mathrm{Kg})$ are shown in Tables 6 and 7, respectively. Gender difference did not significantly influence skin temperature and onset latency of sweat response, but had a significant difference on the total volume of sweat response in all the four recorded regions (Table 6; Figure 2). The median differences at the forearm, proximal leg, distal leg and foot were $0.591 \mu \mathrm{l}, 0.693 \mu \mathrm{l}, 0.696 \mu \mathrm{l}$, and $0.358 \mu \mathrm{l}$, respectively. The BW difference did not have significant influence on skin temperature and onset latency of sweat response, but had a significant influence on the total volume of sweat response in all four recorded regions (Table 7; Figure 3). The median differences at the forearm, proximal leg, distal leg and foot were $0.583 \mu \mathrm{l}$, $0.744 \mu \mathrm{l}, 0.695 \mu \mathrm{l}$ and $0.338 \mu \mathrm{l}$, respectively. Tables 6 and 7 also show that the total volume of sweat response recorded at the foot was the smallest compared to those recorded at other sites (Tables 6 and 7). In terms of sweat response in different age groups by Kruskal-Wallis Test, there was no statistical difference between the five groups (Table 8).

\section{Discussion}

For a PubMed search using the term "Q-Sweat", only two related articles $[8,10]$ can be found. Although QSART is an important tool for ANS evaluation, its clinical utility is still limited by its requisite of specialized equipment and its cost [1,2]. Compared with QSART, the Q-Sweat has a much simpler physiologic set-up. In the meanwhile, the Q-Sweat is reliable, reproducible, and easier to use, operate and maintain. Its study results can be used to estimate the expected QSART findings [8]. However, despite its importance in post-ganglionic sudomotor function evaluation, its clinical use is still limited, at least partially, due to the lack of normal

Table 3 Multiple linear regression "stepwise" analysis for total volumes of sweat response of the four measured sites with sex, age, $\mathrm{BH}, \mathrm{BW}$ and $\mathrm{BMI}$

\begin{tabular}{|c|c|c|c|c|}
\hline Sweat volume $(\mu \mathrm{l})$ & Forearm (Vt1) & Proximal leg (Vt2) & Distal leg (Vt3) & Foot (Vt4) \\
\hline ( $R, R$ square) & $\overline{\text { (weight }=0.465,0.216)}$ & $\overline{\text { (weight }=0.436,0.190)}$ & $\overline{\text { (weight }=0.452,0.204)}$ & (weight; age; sex $=0.556,0.310$ ) \\
\hline $\begin{array}{l}\text { Non-standardized } \\
\text { regression equation }\end{array}$ & $\mathrm{Vt} 1=-0.216+0.017 \times \mathrm{BW}$ & $\mathrm{Vt} 2=0.038+0.014 \times \mathrm{BW}$ & $\mathrm{Vt} 3=-0.175+0.017 \times \mathrm{BW}$ & $\begin{array}{l}\mathrm{Vt} 4=0.213+0.007 \times \mathrm{BW}-0.003 \times \\
\text { age }+0.119 \times \text { gender }\end{array}$ \\
\hline $\begin{array}{l}\text { Standardized } \\
\text { regression equation }\end{array}$ & $\mathrm{Vt} 1=0.465 \times \mathrm{BW}$ & $\mathrm{Vt} 2=0.436 \times \mathrm{BW}$ & $\mathrm{Vt} 3=0.452 \times \mathrm{BW}$ & $\begin{array}{l}\text { Vt } 4=0.319 \times B W-0.186 \times \text { age }+ \\
0.246 \times \text { gender }\end{array}$ \\
\hline
\end{tabular}

Abbreviations: $\mathrm{BH}$, body height; $\mathrm{BW}$, body weight; $\mathrm{BMI}$, body mass index; $\mathrm{Vt}$ 1, square root of total volume of sweat response recorded at forearm; $\mathrm{Vt}$, square root of total volume of sweat response recorded at proximal leg; $\mathrm{Vt} 3$, square root of total volume of sweat response recorded at distal leg; $\mathrm{Vt} 4$, square root of total volume of sweat response recorded at foot. 
Table 4 Linear regression "enter" analysis for the total volumes of sweat response of the four measured sites with age

\begin{tabular}{|c|c|c|c|c|}
\hline Sweat volume $(\mu \mathrm{l})$ & Forearm (Vt1) & Proximal leg (Vt2) & Distal leg (Vt3) & Foot (Vt4) \\
\hline ( $R, R$ square) & $(0.173,0.030)$ & $(0.057,0.003)$ & $(0.119,0.014)$ & $(0.203,0.041)$ \\
\hline Non-standardized regression equation & $\mathrm{Vt1}=0.640+0.005 \times$ age & $\mathrm{Vt} 2=1.007-0.002 \times$ age & $\mathrm{Vt} 3=1.022-0.003 \times$ age & $\mathrm{Vt} 4=0.739-0.004 \times$ age \\
\hline Standardized regression equation & $\mathrm{Vt} 1=0.173 \times \mathrm{age}$ & $\mathrm{Vt} 2=-0.057 \times \mathrm{age}$ & $\mathrm{Vt} 3=-0.119 \times \mathrm{age}$ & $\mathrm{Vt} 4=-0.203 \times$ age \\
\hline
\end{tabular}

Abbreviations: $\mathrm{Vt} 1$, square root of total volume of sweat response recorded at forearm; $\mathrm{Vt} 2$, square root of total volume of sweat response recorded at proximal leg; $\mathrm{Vt} 3$, square root of total volume of sweat response recorded at distal leg; $\mathrm{Vt} 4$, square root of total volume of sweat response recorded at foot.

values for reference, particularly among Asians, including the Chinese, who lack a normative database.

As shown in Tables 6, 7 and 8, the onset latencies of sweat response are around $2.0 \mathrm{~min}$, which is similar to that reported by Sletten et al. [8]. This may suggest that there is no ethnicity difference in sweat onset time. In the present study, the total volume of sweat responses was generally smaller than that reported by Sletten et al. [8]. It is known that different environmental conditions of study may contribute to the different sweat responses. The present study environment has a larger relative humidity $(56 \%[49 \%, 61 \%])$ than that of Sletten et al. (25-35\%) (Tables 5 and 8) [8]. The room temperature of this study environment is $23^{\circ} \mathrm{C}\left(19^{\circ} \mathrm{C}, 27^{\circ} \mathrm{C}\right)$ compared to $23^{\circ} \mathrm{C}$ of Sletten et al. [8]. The influence of relative humidity on physiologic condition has also been reported recently by Maughan et al. [12], who found a similar sweat loss of $60 \%$ but higher sweat rate of $80 \%$ in relative humidity. In the meanwhile, the mean skin temperature was higher in a relative humidity at $80 \%$. Thus, the physiologic responses may explain the relatively higher skin temperature of $35.5-36.0^{\circ} \mathrm{C}$ in the present study compared to the $31.1-32.6^{\circ} \mathrm{C}$ of Sletten et al. [8]. Therefore, the difference in the total volume of sweat response may imply that there is an ethnicity difference in sweat response.

There are studies [13-18] that examine racial or ethnic differences of ANS in different study methods. Although there may be differences in the number of sweat glands among different racial groups, other factors such as acclimatization may also influence the onset and type of sweating processes [15]. In the study of Johnson et al.
[13], there was no significant difference in number of active sweat glands between black and white male subjects. The possible ethnicity difference in sweat response in the Q-Sweat test warrants further large-scale comparison study for better delineation. Nonetheless, the present study shows that the total volume of sweat response recorded at the foot is consistently the smallest when compared to those recorded at the forearm, proximal leg, and distal leg. This finding is also consistent with that reported by Sletten et al. [8] and is important for a relative comparison in an individual if no normal database is available for reference.

Gender difference is an important factor that may influence the total volume of sweat response (Tables 2 and 6), and this effect on sweat response is also noted in other reports $[7,8,19]$. In the present study (Table 6 ), the total volume of sweat response in males is about 2.0 times larger than that of females. This difference may be explained by the larger eccrine sweat gland droplets in men despite the same sweat gland density in both sexes [20].

The BW effect on ANS has been reported before [21] but all of the reported studies focus on cardiovascular responses that show a hyper-active sympathetic response and a hypo-active parasympathetic response. This change of ANS activity can also be observed in weight changes (weight gain or weight loss) [22-24]. The effect of BW on the sweat response has not been previously reported but in the present study, the BW is another factor that may influence the total volume of sweat response. As shown in Table 7, the total volume of sweat response of the participants with $\mathrm{BW} \geq 62 \mathrm{Kg}$ is about

Table 5 Basic information of the participants by body weight $\geq 62$ and $<62 \mathrm{Kg}$

\begin{tabular}{lllll}
\hline Body weight $(\mathbf{K g})$ & Total & $\mathbf{6 2}$ & $<\mathbf{6 2}$ & $\mathbf{7 6}$ \\
\hline Case number & $\mathbf{1 5 0}$ & $\mathbf{7 4}$ & $\mathbf{1 2}$ \\
\hline Gender (male: female) & $\mathbf{7 6 : 7 4}$ & $\mathbf{6 4 : 1 0}$ & $\mathbf{1 0 . 0 0 0 ^ { * }}$ \\
\hline Age $(\mathrm{y} / \mathrm{r})$ & $44.0(22.0,76.0)$ & $44.0(22.0,73.0)$ & $44.0(23.0,76.0)$ & 0.759 \\
\hline Body height $(\mathrm{m})$ & $1.64(1.45,1.84)$ & $1.70(1.48,1.84)$ & $1.58(1.45,1.77)$ & $0.000^{*}$ \\
\hline Body mass index & $22.7(17.1,35.6)$ & $24.2(18.9,35.6)$ & $21.0(17.1,27.8)$ & $0.000^{*}$ \\
\hline Room wet $(\%)$ & $56.0(49.0,61.0)$ & $55.5(49.0,61.0)$ & $56.0(50.0,61.0)$ & 0.254 \\
\hline Room temperature $\left({ }^{\circ} \mathrm{C}\right)$ & $23.0(19.0,27.0)$ & $23.0(19.0,26.0)$ & $23.0(20.0,27.0)$ & 0.577 \\
\hline
\end{tabular}

Data presented as median (maximum, minimum).

Abbreviations: $\mathrm{Kg}$, kilogram; $\mathrm{m}$, meter; Sig, significance as tested by the Mann-Whitney $U$ test.

*Significant correlation at the 0.05 level (2-tailed). 
Table 6 Sweat output detected by Q-sweat and skin temperature over the four skin regions by gender

\begin{tabular}{|c|c|c|c|c|}
\hline & Total & Male & Female & Sig. \\
\hline Number & 150 & 76 & 74 & \\
\hline \multicolumn{5}{|c|}{ Skin temperature $\left({ }^{\circ} \mathrm{C}\right)$} \\
\hline Forearm & $35.8(34.0,37.7)$ & $35.9(34.1,37.7)$ & $35.8(34.0,37.3)$ & 0.484 \\
\hline Proximal leg & $36.2(34.2,38.0)$ & $36.3(34.2,37.7)$ & $36.0(34.5,38.0)$ & 0.126 \\
\hline Distal leg & $35.6(34.0,37.2)$ & $35.7(34.0,37.0)$ & $35.4(34.0,37.2)$ & 0.107 \\
\hline Foot & $35.8(34.0,37.3)$ & $35.8(34.0,37.3)$ & $35.7(34.0,37.2)$ & 0.885 \\
\hline \multicolumn{5}{|c|}{ Onset latency (minute) } \\
\hline Forearm & $2.2(0.6,3.9)$ & $2.1(1.0,3.9)$ & $2.2(0.6,3.5)$ & 0.591 \\
\hline Proximal leg & $1.9(0.7,4.0)$ & $1.8(0.7,2.9)$ & $2.0(0.7,4.0)$ & 0.077 \\
\hline Distal leg & $1.8(0.6,3.8)$ & $1.7(0.7,3.5)$ & $2.0(0.6,3.8)$ & 0.081 \\
\hline Foot & $2.3(0.8,4.4)$ & $2.3(0.8,3.8)$ & $2.2(0.9,4.4)$ & 0.928 \\
\hline \multicolumn{5}{|c|}{ Total sweat volume $(\mu \mathrm{l})$} \\
\hline Forearm & $0.748(0.02,3.983)$ & $1.095(0.023,3.983)$ & $0.504(0.020,3.814)$ & $0.000^{*}$ \\
\hline Proximal leg & $0.825(0.029,4.493)$ & $1.254(0.029,3.753)$ & $0.561(0.060,4.493)$ & $0.000^{*}$ \\
\hline Distal leg & $0.687(0.015,4.914)$ & $1.107(0.043,4.821)$ & $0.411(0.015,4.914)$ & $0.000^{*}$ \\
\hline Foot & $0.294(0.014,1.718)$ & $0.568(0.041,1.718)$ & $0.210(0.014,0.802)$ & $0.000^{*}$ \\
\hline
\end{tabular}

Data presented as median (maximum, minimum).

Abbreviations: Sig, significance tested by the Mann-Whitney $U$ test.

*Significant correlation at the 0.05 level (2-tailed).

2.0 times larger than those of the participants with a $\mathrm{BW}<62 \mathrm{Kg}$. However, there is an uneven distribution of male participants in the body weight groups, with a high percentage $(86 \%, 64 / 74)$ in $\mathrm{BW} \geq 62 \mathrm{Kg}$ group and low percentage $(16 \%, 12 / 76)$ in $\mathrm{BW}<62 \mathrm{Kg}$ (Table 7$)$. This uneven distribution of gender percentage in these two different BW groups may have an influence on the sweat response. Further large scale and more even gender distribution studies are needed to establish a better delineation of the BW influence on sweat response.

The total volume of sweat response has a significant negative regression with age only in the foot site recording (Table 3). Based on analysis of the five separated age groups, aging causes lower total volume of sweat re-

Table 7 Sweat output detected by Q-sweat and skin temperature over four skin regions by BW $\geq 62$ and $<62$ Kg

\begin{tabular}{|c|c|c|c|c|}
\hline Weight (Kg) & Total & $\geq 62$ & $<62$ & Sig. \\
\hline Number & 90 & 74 & 76 & \\
\hline \multicolumn{5}{|c|}{ Skin temperature $\left({ }^{\circ} \mathrm{C}\right)$} \\
\hline Forearm & $35.8(34.0,37.7)$ & $35.8(34.0,37.7)$ & $35.8(34.1,37.3)$ & 0.648 \\
\hline Proximal leg & $36.2(34.2,38.0)$ & $36.3(34.2,37.2)$ & $36.1(34.6,38.0)$ & 0.981 \\
\hline Distal leg & $35.6(34.0,37.2)$ & $35.7(34.0,37.0)$ & $35.5(34.0,37.2)$ & 0.821 \\
\hline Foot & $35.8(34.0,37.3)$ & $35.9(34.0,37.3)$ & $35.6(34.0,37.2)$ & 0.517 \\
\hline \multicolumn{5}{|c|}{ Onset latency (minute) } \\
\hline Forearm & $2.2(0.6,3.9)$ & $2.1(1.0,3.9)$ & $2.2(0.6,3.8)$ & 0.450 \\
\hline Proximal leg & $1.9(0.7,4.0)$ & $1.8(0.7,2.9)$ & $1.9(0.7,4.0)$ & 0.780 \\
\hline Distal leg & $1.8(0.6,3.8)$ & $1.7(0.6,3.5)$ & $2.0(0.6,3.8)$ & 0.588 \\
\hline Foot & $2.3(0.8,4.4)$ & $2.3(0.8,3.8)$ & $2.3(0.9,4.4)$ & 0.762 \\
\hline \multicolumn{5}{|c|}{ Total sweat volume $(\mu \mathrm{l})$} \\
\hline Forearm & $0.748(0.020,3.983)$ & $1.038(0.023,3.983)$ & $0.500(0.020,1.872)$ & $0.000^{*}$ \\
\hline Proximal leg & $0.825(0.029,4.493)$ & $1.282(0.029,4.493)$ & $0.538(0.060,2.821)$ & $0.000^{*}$ \\
\hline Distal leg & $0.687(0.015,4.914)$ & $1.107(0.043,4.914)$ & $0.412(0.015,2.902)$ & $0.000^{*}$ \\
\hline$\overline{\text { Foot }}$ & $0.294(0.014,1.718)$ & $0.542(0.032,1.718)$ & $0.204(0.014,0.952)$ & $0.000^{*}$ \\
\hline
\end{tabular}

Data presented as median (maximum, minimum).

Abbreviations: Kg, kilograms; BW, body weight; Sig, significance tested by the Mann-Whitney $U$ test.

*Significant correlation at the 0.05 level (2-tailed). 


\section{Gender}

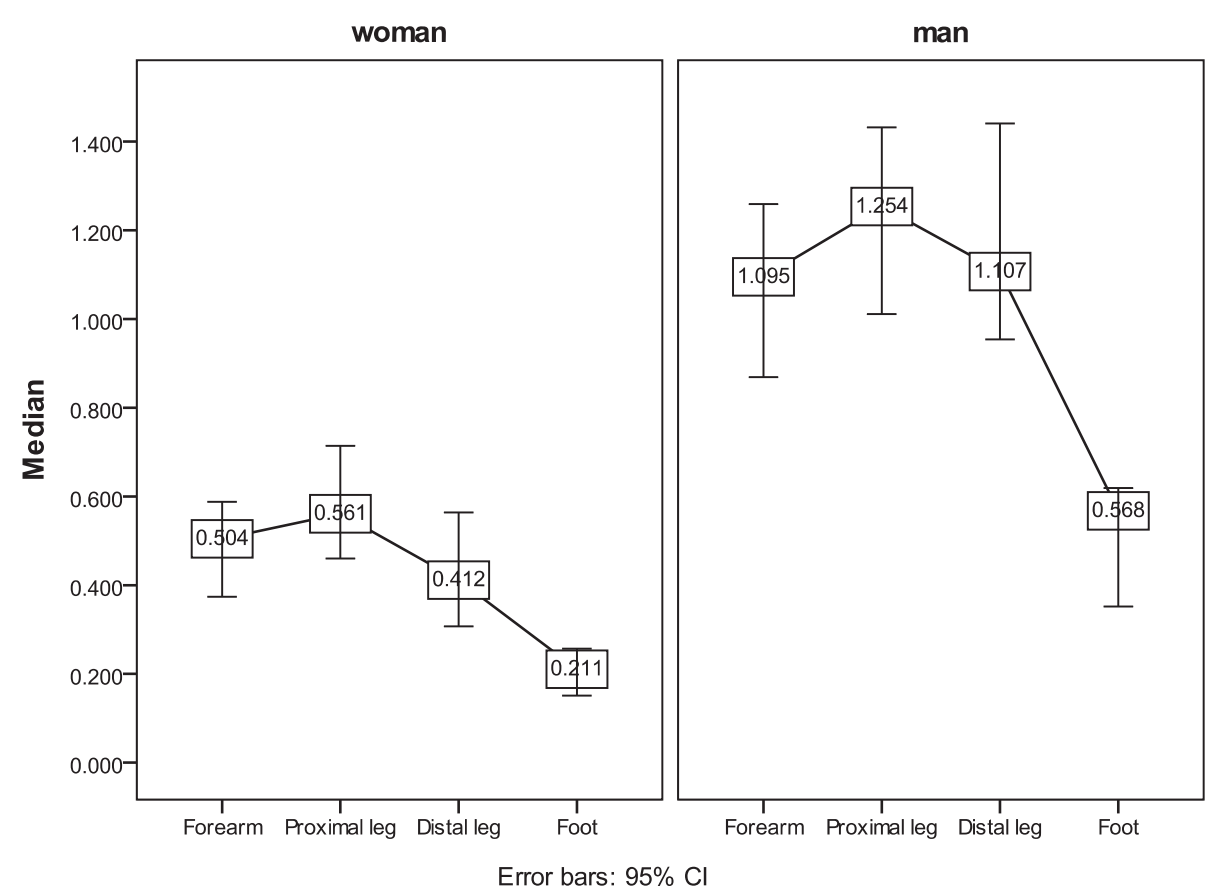

Figure 2 Difference in total volume of sweat response by gender (unit: $\boldsymbol{\mu l}$ ). The median sweat output volume in males was larger than that of females. Cl, confidence interval.

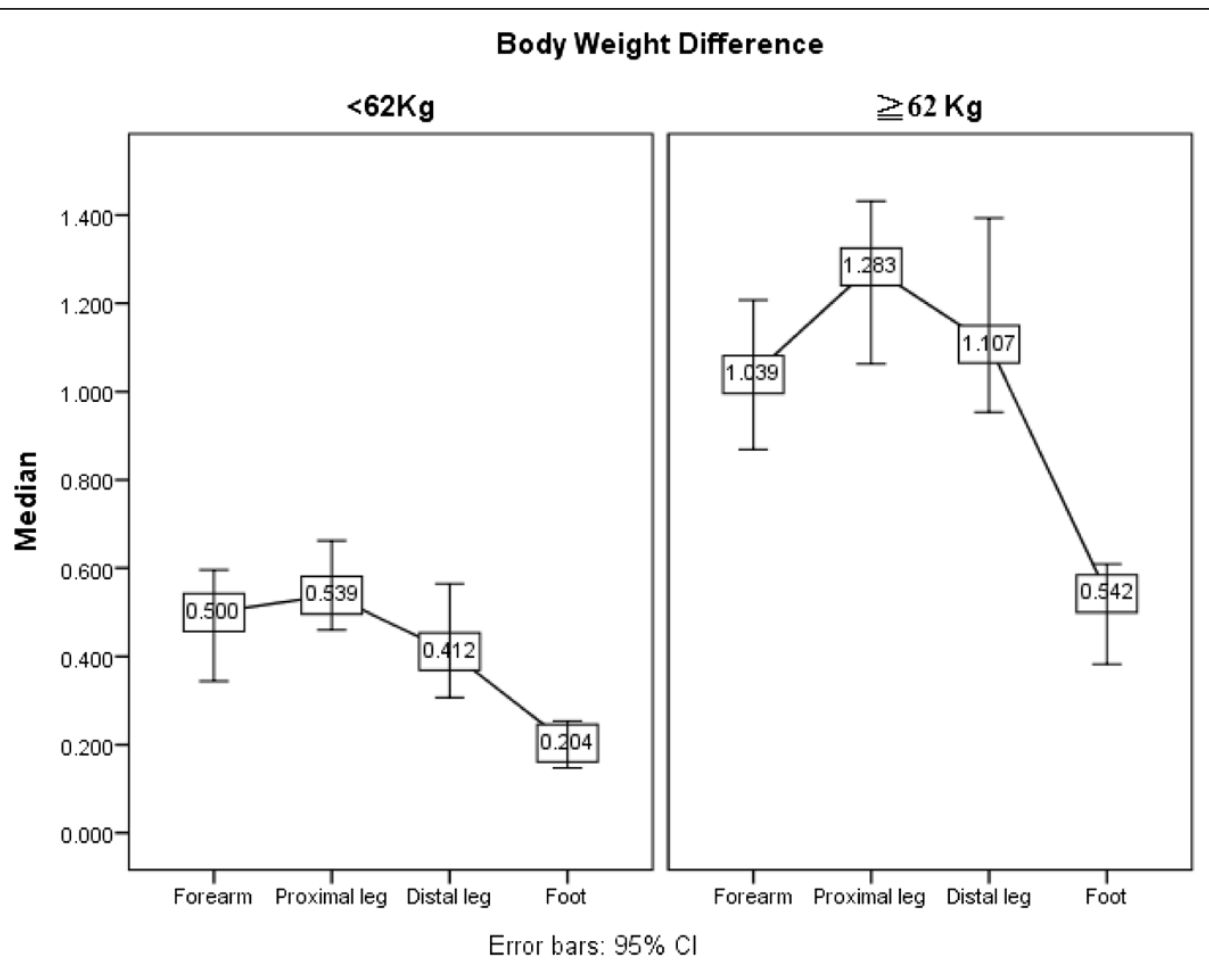

Figure 3 Difference in total volume of sweat response by body weight difference ( $\geq \mathbf{6 2}$ and $<\mathbf{6 2}$ kilograms [kg]) (unit: $\boldsymbol{\mu l}$ ). The median sweat output volume of the participants with body weight $\geq 62 \mathrm{~kg}$ was larger than that of participants with $<62 \mathrm{~kg}$ body weight. Cl, confidence interval. 
Table 8 Sweat output responses detected by Q-Sweat device of the five different age groups

\begin{tabular}{|c|c|c|c|c|c|c|}
\hline Age Range & $21-30$ & $31-40$ & 41-50 & $51-60$ & $\geq 61$ & Sig. \\
\hline Number & 30 & 36 & 31 & 32 & 21 & K-W \\
\hline \multicolumn{7}{|l|}{ Gender } \\
\hline (men: women) & $15: 15$ & $20: 16$ & $16: 15$ & $15: 17$ & $10: 11$ & 0.961 \\
\hline Height (m) & $1.69(1.49,1.83)$ & $1.66(1.52,1.83)$ & $1.65(1.53,1.84)$ & $1.61(1.45,1.80)$ & $1.57(1.48,1.72)$ & $0.003^{*}$ \\
\hline Weight (Kg) & $63.0(46.0,85.0)$ & $61.0(46.0,95.0)$ & $60.0(45.0,89.0)$ & $62.0(47.0,87.8)$ & $61.2(47.0,89.0)$ & 0.919 \\
\hline Body Mass Index & $21.8(17.9,26.8)$ & $21.9(18.1,34.9)$ & $22.0(17.1,31.5)$ & $23.3(19.3,35.6)$ & $23.1(18.6,31.5)$ & $0.041^{*}$ \\
\hline Room Wet (\%) & $56.0(51.0,61.0)$ & $56.0(50.0,60.0)$ & $56.0(53.0,61.0)$ & $56.0(49.0,60.0)$ & $56.0(54.0,60.0)$ & 0.824 \\
\hline $\mathrm{RT}\left({ }^{\circ} \mathrm{C}\right)$ & $23.0(21.0,25.0)$ & $22.0(19.0,27.0)$ & $22.0(20.0,26.0)$ & $22.0(21.0,26.0)$ & $22.0(21.0,24.0)$ & 0.560 \\
\hline \multicolumn{7}{|c|}{ Skin temperature $\left({ }^{\circ} \mathrm{C}\right)$} \\
\hline Forearm & $35.8(34.1,37.0)$ & $35.9(34.1,37.3)$ & $35.8(34.3,37.3)$ & $35.8(34.0,37.0)$ & $36.4(34.5,37.7)$ & 0.620 \\
\hline Proximal leg & $36.0(34.9,36.7)$ & $35.9(34.6,37.6)$ & $36.1(34.2,37.7)$ & $36.0(34.5,36.9)$ & $36.0(35.6,38.0)$ & 0.964 \\
\hline Distal leg & $35.4(34.0,36.6)$ & $35.4(34.1,36.9)$ & $35.6(34.1,36.8)$ & $35.7(34.3,37.2)$ & $35.6(34.0,37.0)$ & 0.635 \\
\hline Foot & $36.0(34.3,36.8)$ & $35.4(34.0,37.2)$ & $35.7(34.0,37.2)$ & $35.7(34.1,36.9)$ & $36.0(34.0,37.3)$ & 0.241 \\
\hline \multicolumn{7}{|c|}{ Onset latency (minute) } \\
\hline Forearm & $2.2(0.8,3.9)$ & $2.3(1.7,3.8)$ & $2.1(0.8,3.5)$ & $2.1(0.6,3.1)$ & $2.1(1.3,3.1)$ & 0.164 \\
\hline Proximal leg & $1.9(0.7,3.4)$ & $1.9(1.0,4.0)$ & $1.9(0.7,3.2)$ & $1.8(1.0,2.6)$ & $2.0(1.0,2.8)$ & 0.945 \\
\hline Distal leg & $2.2(1.0,3.2)$ & $2.0(0.7,3.8)$ & $1.7(0.8,3.0)$ & $1.6(0.6,3.5)$ & $1.9(0.6,2.8)$ & 0.088 \\
\hline Foot & $2.2(1.0,3.8)$ & $2.3(0.8,3.6)$ & $2.1(1.0,3.3)$ & $2.4(0.9,4.4)$ & $2.5(1.3,3.6)$ & 0.099 \\
\hline \multicolumn{7}{|l|}{ Total Volume $(\mu \mathrm{l})$} \\
\hline Forearm & $0.594(0.029,3.983)$ & $0.590(0.020,2.810)$ & $0.873(0.044,3.018)$ & $0.872(0.128,3.919)$ & $0.887(0.191,2.416)$ & 0.366 \\
\hline Proximal leg & $1.068(0.071,2.755)$ & $0.781(0.029,2.607)$ & $0.657(0.090,2.821)$ & $0.981(0.108,4.493)$ & $0.662(0.215,1.697)$ & 0.545 \\
\hline Distal leg & $0.814(0.295,2.366)$ & $0.635(0.015,2.902)$ & $0.648(0.107,2.711)$ & $0.763(0.047,4.914)$ & $0.398(0.084,1.895)$ & 0.322 \\
\hline Foot & $0.376(0.114,1.095)$ & $0.302(0.014,1.456)$ & $0.296(0.032,1.718)$ & $0.284(0.036,1.281)$ & $0.212(0.045,0.609)$ & 0.152 \\
\hline
\end{tabular}

Data presented as median (maximum, minimum).

Abbreviations: K-W, Kruskal-Wallis Test; RT, Room Temperature; Sig, significance tested by the Kruskal-Wallis Test.

*Significant correlation at the 0.05 level (2-tailed.

sponse in the foot site recordings (Table 8). Although this finding did not reach statistical significance, this effect of age on total volume of sweat response is also noted in others studies $[7,19]$ whereby there is a progressive decline in the total volume of sweat response with age in all three lower extremity sites but not the forearm sites. In Table 4, the influence of age may have a similar effect on sweat response, but this difference cannot be drawn from the analysis shown in Table 8 because of the limited participants aged $>60$ years. In the report of Low et al. [19], aging has been shown to have selective influence on ANS activities. Of these, cardiovagal function is known to be influenced significantly but not sweat response [3]. But as shown in the reports of Holowatt et al. [25] and Kihara et al. [26], aging may influence the sweat function.

The present study has limitations. First, the case number in the aged participants with complete normal ANS is limited. Second, there is an uneven distribution and gender and BW difference in the study groups. Third, the difference in laterality or sidedness is not examined. Lastly, participants of other ethnicities have not been included for comparison. Further large-scale study is needed to examine the sweat response of different groups of participants.

\section{Conclusions}

Using the Q-Sweat study to evaluate the post-ganglionic sudomotor function by measuring sweat response, this study reveals the effect of gender on sweat response. The BW effect on sweat response can be influenced indirectly by the gender effect. This study also demonstrates that the total volume of sweat response recorded at the foot is consistently the smallest compared to those recorded at the forearm, proximal leg, and distal leg. This is the first report to show a normative database of sweat response evaluated using Q-Sweat devices among the Chinese. This normative database can be used for further post-ganglionic sudomotor research or clinical practice involving a Chinese population.

\section{Competing interests}

All of the authors declare no competing or conflicts of interests.

\section{Authors' contributions}

All authors have read and approved the submitted manuscript. CSF and CYT contributed to the conception and design, data acquisition and analysis, and drafting and revision of the manuscript; LCH, HCR, TNW, CCC, and HCC 
contributed to the conception and design, and clinical data analysis; and CYC and CWN contributed to the conception and design, data analysis, and critical revision and final approval of the manuscript.

\section{Acknowledgements}

The authors wish to thank all the participants for their time and commitment to this research. This study was supported in part by research grants CMRPG880841 and CMRPG880821 to Y.C.C. from the Kaohsiung Chang Gung Memorial Hospital.

\section{Author details}

${ }^{1}$ Department of Neurology, Kaohsiung Chang Gung Memorial Hospital and Chang Gung University College of Medicine, Kaohsiung, Taiwan. ${ }^{2}$ Department of Biological Science, National Sun Yat-Sen University, Kaohsiung, Taiwan.

Received: 13 January 2012 Accepted: 11 May 2012 Published: 8 June 2012

\section{References}

1. Low PA: Evaluation of sudomotor function. Clin Neurophysio/ 2004, 115:1506-1513.

2. Illigens BMW, Gibbons $\mathrm{CH}$ : Sweating testing to evaluate autonomic function. Clin Auton Res 2009, 19:79-88.

3. Low PA, Caskey PE, Tuck RR, Fealey RD, Dyck PJ: Quantitative sudomotor axon reflex test in normal and neuropathic subjects. Ann Neurol 1983, 14:573-580.

4. Low PA, Zimmeman BR, Dyck PJ: Comparison of distal sympathetic with vagal function in diabetic neuropathy. Muscle Nerve 1986, 9:592-596.

5. Stewart JD, Low PA, Fealey RD: Small-fiber peripheral neuropathy: diagnostic value of sweat tests and autonomic cardiovascular reflexes. Ann Neurol 1989, 26:145A.

6. Low VA, Sandroni P, Dealey RD, Low PA: Detection of small fiber neuropathy by sudomotor testing. Muscle Nerve 2006, 34:57-61.

7. Low PA, Denq JC, Opfer-Gehrking TL, Dyck PJ, O'Brien PC, Slezak JM: Effect of age and gender on sudomotor and cardio-vagal function and blood pressure response to tilt in normal subjects. Muscle Nerve 1997, 20:1561-1568.

8. Sletten DM, Weigand SD, Low PA: Relationship of Q-Sweat to quantitative sudomotor axon reflex test (QSART) volumes. Muscle Nerve 2010, 41:240-246.

9. Low PA: Laboratory evaluation of autonomic failure. In Clinical autonomic disorders: evaluation and management. Edited by Low PA. Boston, MA: Little, Brown and Company; 1993:169-195.

10. Chen SF, Tsai NW, Chang CC, Lu CH, Huang CR, Chuang YC, Chang WN: Neuromuscular abnormality and autonomic dysfunction in patients with cerebrotendinous xanthomatosis. BMC Neurol 2011, 11:63.

11. Low PA: Testing the autonomic nervous system. Semin Neurol 2003, 23:407-421.

12. Maughan RJ, Otani H, Watson P: Influence of relative humidity on prolonged exercise capacity in a warm environment. Eur J Appl Physio 2011, Epub ahead of print.

13. Johnson LC, Landon MM: Eccrine sweat gland activity and racial differences in resting skin conductance. Psychophysiology 1965, 1:322-329.

14. Reilly DM, Ferdinando D, Johnston C, Shaw C, Buchanan KD, Green MR: The epidermal nerve fiber network: characterization of nerve fibers in human skin by confocal microscopy and assessment of racial variations. $\mathrm{Br} J$ Dermatol 1997, 137:163-170

15. Rawlings AV: Ethnic skin types: are there differences in skin structure and function?. Int J Cosmet Sci 2006, 28:79-93.

16. Parmer RJ, Cervenka JH, Stone RA, O'Connor DT: Autonomic function in hypertension. Are there racial differences?. Circulation 1990, 81:1305-1311.

17. Ergul A: Hypertension in black patients: an emerging role of the endothelin system in salt-sensitive hypertension. Hypertension 2000, 36:62-67.

18. Lee JB, Bae JS, Matsumoto T, Yang HM, Min YK: Tropical Malaysians and temperate Koreans exhibit significant differences in sweating sensitivity in response to iontophoretically administered acetycholine. Int J Biometerol 2009, 53:149-157.
19. Low PA, Opfer-Gehrking TL, Proper CJ, Zimmerman I: The effect of aging on cardiac autonomic and post-ganglionic sudomotor function. Muscle Nerve 1990, 12:152-157.

20. Kihara M, Opfer-Gehrking TL, Low PA: Comparison of directly stimulated with axon reflex-mediated sudomotor responses in human subjects and in patients with diabetes. Muscle Nerve 1993, 16:655-660.

21. Thayer JF, Yamomoto SS, Brosschot JF: The relationship of autonomic imbalance, heart rate variability and cardiovascular disease risk factors. Int J Cardiol 2010, 28:122-131.

22. Faqius J: Sympathetic nerve activity in metabolic control-some basic concepts. Acta Physio/ Scand 2003, 177:337-343.

23. Huqqett RJ, Burns J, Mackintosh AF, Mary DA: Sympathetic neural activation in non-diabetic metabolic syndrome and its further augmentation by hypertension. Hypertension 2004, 44:847-852.

24. Straznicky NE, Lambert GW, Lambert EA: Neuro-adrenergic dysfunction in obesity: an overview of the effects of weight loss. Curr Opin Lipidol 2010, 21:21-30.

25. Holowatt LA, Kenney WL: Peripheral mechanism of thermoregulatory control of skin blood flow in aged humans. J Appl Physiol 2010, 109:1538-1544.

26. Kihara M, Takahashi M, Nishimoto K, Okuda K, Matsui T, Yamakawai T, Okumura A: Autonomic dysfunction in elderly bedfast patients. Age Ageing 1998, 27:551-555.

\section{doi:10.1186/1471-2202-13-62}

Cite this article as: Chen et al:: Sweat output measurement of the postganglion sudomotor response by Q-Sweat Test: a normative database of Chinese individuals. BMC Neuroscience 2012 13:62.

\section{Submit your next manuscript to BioMed Central and take full advantage of:}

- Convenient online submission

- Thorough peer review

- No space constraints or color figure charges

- Immediate publication on acceptance

- Inclusion in PubMed, CAS, Scopus and Google Scholar

- Research which is freely available for redistribution 